\title{
Power, Control, and Marital Violence; Beliefs vs. Behavior. A Test of the Graham-Kevan Archer Measure
}

\author{
Clifton R. Emery ${ }^{1, *}$, Shali $\mathrm{Wu}^{2}$, Hotaek Lee ${ }^{3}$, Hyerin $\mathrm{Yang}^{3}$, Hai Nguyen Trung $^{3}$ and \\ Jaeyop $\mathrm{Kim}^{3}$
}

${ }^{1}$ Graduate School of Social Welfare, Yonsei University and Special Term Research Associate in Psychology, Tsinghua University (Beijing), Seoul, Korea

${ }^{2}$ Tsinghua University, SEM, Beijing, China

${ }^{3}$ Yonsei University, Seoul, Korea

\begin{abstract}
We argue that Western conceptualizations of a common couple violence/intimate terrorism divide in domestic violence categories may be ill-suited to the Korean context because they are rooted in psychopathological explanations of control motivation (Holtzworth-Munroe \& Stuart, 1994; Johnson, 2008). Control motivation in Korea may be more related to the cultural necessity of keeping face in a normatively patriarchal context rather than the attachment issues suggested by Holtzworth-Munroe and Stuart (1994). To examine the power and control context of domestic violence in Korea, we implemented Graham-Kevan and Archer's (2003) measure on a sample of 77 Korean students at an elite university in Seoul. We used cluster analysis to separate the sample into high and low control cluster families. The high control cluster was associated with more domestic violence, more violence by the husband, more injuries from violence, and marginally more child abuse. Contrary to our prediction, being in the high control cluster appears to be a more important predictor of domestic violence than patriarchal beliefs. Implications and limitations are discussed.
\end{abstract}

Keywords: Marital violence, domestic violence, patriarchal beliefs, controlling behaviors.

Criminology typically locates explanations for domestic violence in the social disorganization literature (cf. Browning, 2002), conceptualizing it as a form of disorder. Feminist theory, on the other hand, tends to locate explanations for domestic violence in pathological control, conceptualizing it as a form of 'deviant order' (Emery, 2011). Past typologies of domestic violence tend to draw on the latter body of theory rather than the former. Although it has been nearly 17 years since Johnson (1995) introduced the idea of two conceptually distinct forms of domestic violence, research on the distinction between intimate terrorism and common couple violence (Johnson, 2008 ) is still in the early stages. Johnson (1995) argued that two etiologically distinct types of domestic violence existed. Common couple violence was theorized as a less severe form of domestic violence, perpetrated equally by men and women, and with causal roots in poor communication and anger management skills. Intimate terrorism, on the other hand, was theorized to be more severe, perpetrated primarily by men, and had causal roots in a pathological need to control one's partner (Holtzworth-Munroe \& Stuart, 1994; Johnson, 1995). Implications for prognosis and intervention differ considerably between the two types, intimate terrorism being more deadly and difficult to intervene against.

*Address corresponding to this author at the Graduate School of Social Welfare, Yonsei University and Special Term Research Associate in Psychology, Tsinghua University (Beijing), Seoul, Korea; Tel: 02-2123-6216; E-mail: cemery@yonsei.ac.kr
If research on these types remains in its infancy in the west, still less research has been done on the extent to which this distinction holds in cultures rooted in Confucian familism (Chang, 2003). The rate of domestic violence in South Korea is high; the most current estimates are that about $20 \%$ of married Korean women experience physical violence at the hands of their husbands each year (김재엽 et al., 2010). It is unclear, however, whether these high rates are more a product of 'cultural residues' (Kim \& Sung, 2000) or higher rates of the psychopathological phenomena implied by Johnson's concept of controlmotivated violence. ${ }^{1}$ This paper provides a preliminary examination of this question for the Korean case. It begins with an overview of Graham-Kevan and Archer's (2003) findings. It then discusses how and why the intimate-terrorism construct may be inappropriate for the Korean case. Analyses first replicate analyses of Graham-Kevan and Archer (2003) using their measure of power and control. The paper

\footnotetext{
${ }^{1} J o h n s o n$ (2008) locates his concept of Intimate Terrorism in the context of clinical and community studies of batterers (Holtzworth-Munroe et al., 2000) which used cluster analysis to separate groups of men mandated to battere treatment programs. Research on these samples separated garden variety type batterers from what Holtzworth-Munroe and Stuart (1994) described as borderline-dysphoric batterers. The borderline type, they argued, was characterized by a deep-seated psychological need to control their partners in order to achieve felt-security. This pattern may have origins in childhood attachment disorders (Holtzworth-Munroe \& Stuart, 1994). By implication, Johnson's (2008) intimate terrorist construct stresses a psychological desire for control, rather than one mainly constructed by social norms. See Emery (2011) for further discussion of this distinction.
} 
then examines the relationship between domestic violence and Jaeyop Kim's measure of patriarchal beliefs.

Domestic violence is a serious problem in South Korea. Although the most recent studies find the annual rate of violence to be $20 \%$ (김재엽 et al., 2010), it has recently been estimated to be as high as $32 \%$ (Kim \& Emery, 2003), and other research suggests that the rate of domestic violence among Koreans compares unfavorably to the rate among Chinese (Kim, Park, \& Emery, 2009). Some scholars argue that these high rates are caused by higher amounts of marital conflict stemming from conflict over traditional versus modern norms about sex roles (김재엽, 김희진, 최장원, 2010). Whatever the causes, the high rate of physical violence has been linked to higher rates of depression, stress, and aggression in Korean women (Kim, Park \& Emery, 2009). Domestic violence in Korea has also been linked to lower marital stability (김정옥, 전형미, 이현혜, 1992) and higher rates of internet addiction among exposed children (조춘범, 2007).

The problem of domestic violence in South Korea is thus one for serious study. Unfortunately, little research to date has examined whether typologies of domestic violence used in western countries hold for East Asia in general and South Korea in particular. One of the most well-known typologies centers around Johnson's (2008) concept of control motivation. Only one study we could find thoroughly measured this concept in a Korean context. In a comparative study of dating violence, Gover, Jennings, Tomsich, Park, and Rennison (2011) examined the Graham-Kevan and Archer (2003) measure of power and control in a sample of Koreans and Americans. They found that controlling behavior was associated with childhood physical abuse, risky sexual behavior, low self control, serious dating, and gender in both Korea and the US. However, Gover et al. (2011) conceptualized the control as psychological abuse, rather than as indicator of an intimate terrorism type of domestic violence. This approach fails to shed much light on the appropriateness of using Johnson's (2008) concept of control motivated violence in Korea.

Graham-Kevan and Archer (2003) developed the scale of power and control based on the Power and Control Wheel (Pence and Paymar (1993). They found substantial broad support for Johnson's (1995) contention that domestic violence can be fruitfully divided into common couple violence and intimate terrorism subtypes in a British sample (Graham-Kevan
\& Archer, 2003). Following Johnson's (1995) arguments about the characteristics of intimate terrorism, Graham-Kevan and Archer (2003) found violence occurred in both high and low control contexts (hypothesis 1 in this paper), that intimate terrorism is perpetrated primarily by males and that the role of gender in perpetration was significantly different by relationship type (hypothesis 2). They found that violence in high-control contexts was more likely be frequent (hypothesis 3) to escalate (hypothesis 4) and produce injuries (hypothesis 5), and that victims of high-control type violence were less likely to use violence in retaliation (hypothesis 6). Finally, they found acts of violence to be sex-symmetric in survey samples and male dominated in shelter samples (not testable in this paper).

Graham-Kevan and Archer's (2003) findings are extremely important, but must be evaluated with respect to the Korean context before their findings can be appropriately interpreted for the Korean case. For example, in Korean culture it is normal for women to control the money, rather than men (Hogarth, nd). This may result in little variation on the Graham-Kevan and Archer (2003) items pertaining to economic control.

A more fundamental concern remains however. Johnson's (2008) distinction between common (situational) couple violence perpetrators and intimate terrorists is rooted in the empirical research of Holtzworth-Munroe et al. (2000). Based on cluster analysis, they divided batterers into 3 types. In Johnson's (2008) terms, these are situational couple violence, dependent, and anti-social types. In mapping his typology directly onto Hotzworth-Munroe et al.'s (2000), Johnson locates the etiology of intimate terrorism in psychopathology. As we have argued elsewhere (see Emery, 2011), this substantially downplays possible social explanations rooted in socially constructed, rather than psychopathologically constructed, control needs. It may well be that in Western cultures where patriarchal beliefs have long been in abeyance control needs rooted in psychopathology may be most important. That is, the control needs of intimate terrorists in western countries may indeed stem from psychopathology.

This may not be the case for South Korea however. It is possible that in Korea, as in other places, some men's motivation to control their wives may be more socially constructed. Although not desperate for control of intimates as a means of achieving felt-security to 
remedy insecure attachment (see Cassidy \& Shaver, 1999), some men may be motivated to use violent control of their wives because of social norms that dictate men should have control. In short, control needs in Korea may be more rooted in cultural needs for face (Lim \& Choi, 1996) rather than psychopathology.

In Korea, violent control motivation may be rooted in a combination of cultural emphases on preservation of face and patriarchal norms that construct male dominance as an ideal. Indeed, Kim and Sung (2000) argue high rates of domestic violence among Korean American families stem from a 'residue' of patriarchal tradition and Emery et al. (2012) find a strong relationship between patriarchal beliefs and male perpetrated domestic violence in Korea. Thus, some men may indeed be motivated to control their intimate partners as a result of underlying psychopathology, but others may be motivated by a simpler social motive of saving face in front of friends, neighbors and family members when patriarchal norms are present. If this latter mechanism is more present in Korea than in the West, Johnson's (2008) typology, as well as GrahamKevan and Archer's (2003) measure, may be less useful for the Korean case. That is, patriarchal beliefs may have more explanatory power for domestic violence in Korea than control needs, but the opposite may be the case in the west. It is thus important to examine the extent to which Graham-Kevan and Archer's (2003) control measure, versus patriarchal beliefs (Emery et al., 2012) has explanatory power for domestic violence in Korea.

Patriarchal sex roles are only one aspect of Confucian family culture. Other aspects include filial piety, respect for learning, and an emphasis on harmonious relationships (Ornatowski, 1996). Responses to controlling behavior may cause respondents draw upon ideals of harmony to simply comply and avoid rocking the boat. However, violence itself seems likely to undermine harmony ideals.

\section{HYPOTHESES}

Following Graham-Kevan and Archer (2003) we hypothesize that among Korean families:

1) Marital violence will occur in both high and low control contexts

2) Control will be positively associated with more violence by the male partner and less by the female partner.
3) Control will be positively associated with frequent aggression.

3a) The correlation will be similar between father's controlling behavior and father violence and mother's controlling behavior and mother's violence (replicates Straus, 2008).

4) Control will be positively associated with escalation of violence.

5) Control will be positively associated with injury.

6) Victims of control will be less violent than other victims.

Based on previous research, we also hypothesize:

7) Control will be positively associated with offspring patriarchal beliefs.

8) Control will be positively associated with offspring family harmony ideals.

9) Control will be positively associated with child abuse.

10) Offspring family harmony ideals will be negatively associated with domestic violence.

11) Patriarchal beliefs will be more strongly (positively) associated with marital violence than the controlling behaviors scale (difference in proportions/R-squared test).

\section{METHOD}

\section{Data}

The data consist of a cluster sample of 77 Korean students from an elite Korean university. A simple random sample from the list of departments was drawn. Participants were recruited from courses within selected departments during the Spring semester, 2011. They were not given course credit, but were given small incentives (chocolate) for participation. Although reporting on parents' IPV by older children may seem somewhat unusual, Hamby, Finkelhor, Turner, and Omrod (2010) interviewed both caregivers and older children about parents IPV and found no evidence of response bias. Respondents were $29 \%$ female and $71 \%$ male. The mean age was 22 years old. All participants were children of intact marriages. However, 4 participants indicated they did not live with 
their fathers, one indicated the mother was not present in the home. Two participants lived with grandparents. The reported average household income was about 4.5 million won per month (approximately US\$4200). On average, households were composed of 3.6 family members.

\section{Measures}

\section{Marital Violence}

The measure of marital violence is the adult child's report on their parents of a Korean translation of Straus, Hamby, Boney-McCoy and Sugarman's (1996) Conflict Tactics Scale (CTS) 2. The eight physical violence Likert Scale items (threw something at partner, pushed or grabbed, slapped, kicked/bit/hit with fist, beat up, choked, and used or threatened to use a knife or gun) and two injury items were collapsed into 'total in last year' measure. Frequency scores of these were added up to create the total violence and male violence scales. The Conflict Tactics Scale has adequate evidence of construct validity (Straus \& Gelles, 1990). It is also reasonably reliable (Cronbach's $\alpha=.70)$.

\section{Controlling Behaviors Scale}

Graham-Kevan and Archer's (2003) measure of controlling behaviors is based on the power and control wheel found in Pence and Paymar (1993). It is divided into 5 subscales. The overall reliability of the scale was high (Cronbach's $\alpha=.88$ ). One item from the GrahamKevan and Archer (2003) measure ("Threatened to report the other to welfare") was omitted because it was inappropriate for the Korean case.

The economic subscale is composed of (1) Did your father/mother ever disapprove of the other working/studying?", (2) "If yes, did they try to make the work/study of the other difficult?", (3) "Did your father/mother feel it was necessary to have control over the other's money?", (4) "If yes, did your father/mother give the other an allowance?", (5) "Did your father/mother have knowledge of the family income?". The threats subscale is composed of (6) "Did your father/mother make or carry out threats to do something to harm the other?", (7) "Did your father/mother threaten to leave the other?", (8) "Did your father/mother threaten to commit suicide?", (9) "Did your father/mother encourage the other to do illegal things s/he would not otherwise have done?" The intimidation subscale is composed of (10) "Did your father/mother use looks, actions and/or gestures to change the behavior of the other?", (11) "If yes, did this make the other afraid?", and (12)"Did your father/mother smash property when annoyed or angry?", (13) "If yes, was it the other's property?"

The emotional control subscale was composed of (14) "Did your mother/father put down the other when they felt the other was 'getting too big for their boots'?", (15) "If yes, did your mother/father put the other down in front of others (friends, family children)", (16) Did your mother/father try to humiliate the other in front of others?", (17) "Did your mother/father tell the other s/he was going crazy?", (18) "Did your father/mother call the other unpleasant names?".

The Isolation subscale was composed of (19) "Did your mother/father restrict the amount of time the other spent with friends and/or family" (20) "If your mother/father went out, did the other want to know where s/he went and whom he or she spoke to?", (21) "Did your father/mother limit the other's activities outside of the relationship?", (22) "Did your father/mother feel suspicious/jealous of the other?" and (23) "If yes, was this used as a reason to monitor and control the activities of the other?".

A five-factor solution factor analysis (varimax rotation) was carried out to examine whether the covariance pattern in the data matched the theoretical subscales. It did not, and only $53 \%$ of the variance was explained. Factor loadings from the analysis are provided in Table 1 below.

In keeping with standard practice in factor analysis, very low loadings are omitted. If we use .7 as a cutoff, the first factor is mainly a combination of making work or study difficult, threatening to leave or threatening suicide. Thus it is a mix of the Economic and Threat subscales. The second factor is mainly a function of suspicion and consequent control and monitoring. The second factor corresponds to isolation, but excludes 3 of the 5 items. The other items for the subscale may be extraneous. The third factor is dominated by putting the partner down and doing so in front of others on the Emotional subscale, indicating that calling the other parent crazy and name calling may not explain much variance. The fourth factor is dominated by control of the money and allowancing (corresponding to the Economic subscale), and the fifth factor is mainly a function of smashing the other's property (which corresponds to the intimidation subscale).

The factor analysis findings suggest the possibility that some items (with consistently low loadings) may 
Table 1: Varimax Rotation Factor Analysis

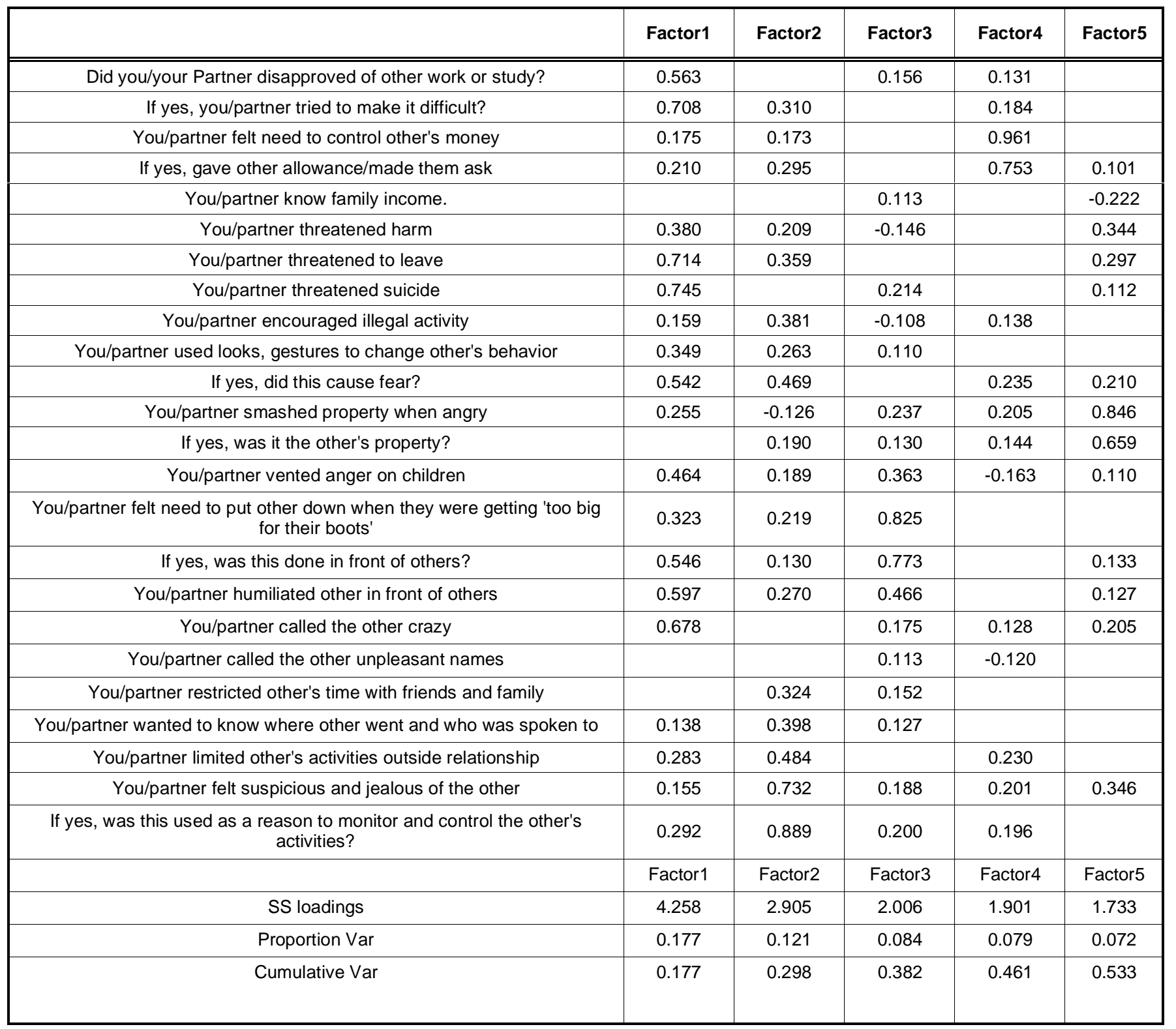

be fruitfully omitted when studying Korean families. Other subscales may require re-conceptualization. Factor 1, for example, which has high loadings for several of the subscales suggested by Graham-Kevan and Archer (2003), may be capturing passiveaggressive manipulation tactics rather than any of the Graham-Kevan and Archer (2003) subscales. Unfortunately, factor analysis results are not reported by Graham-Kevan and Archer (2003), making comparison with their data impossible.

\section{Patriarchal Beliefs Scale}

The patriarchal beliefs scale follows that used in Emery et al., (2012). These capture the participants' patriarchal beliefs. These Likert scale items include (1) men should be the leaders in society, (2) men should be dominant in sex, (3) wives should do most of the household chores, (4) a family's economic decisions should be made by the husband, (5) wives should follow their husbands' decisions about whether the wife can have a job (6) important decisions about the children, education and employment should be made by the husband, and (7) husbands sometimes need to use violence against wives to preserve the husband's authority. The scale had good reliability (Cronbach's a $=.87$ ).

\section{Confucian Family Harmony Scale}

Ornatowski (1996) characterized Confucianism according to 3 dimensions (1) respect for learning, (2) 
filial piety, and (3) harmonious relationships. The Confucian Family Harmony Scale is intended to capture the harmony dimension of Confucian culture. It is a modified version of Heller's (1976) familism measure. The items in this Likert scale measure include: (1) Maintaining family harmony is very important, (2) Maintaining good relationships in the family is more important than frank expression of one's opinion, (3), In families, it's more important to avoid conflict than to speak your mind, (4) I sometimes don't say what I think in order to avoid offending family members, (5) It is important to make sacrifices for one's family, (6) The family is more important than the individual (7) Family considerations should come before individual wants and needs, (8) It is the responsibility of children to be with their parents in time of serious illness, (9) As many activities as possible should be shared by married children and their parents, (10) A married person should be willing to share the home with the parents of his or her spouse, (11) A married person should be willing to share the home with the brothers and sisters of his or her spouse, and (12) Children of elderly parents have as much responsibility for the welfare of their parents as they have for the welfare of their own children. The scale had acceptable reliability (Cronbach's $\alpha=.71$ ).

\section{Child Abuse Measure}

Parental violence against the child was measured using a Korean version of the Parent-Child CTS short form (Straus \& Mattingly, 2007). The two measures of physical abuse on this ten item scale were: (1) Hit /him/her on some other part of the body besides the bottom with something like a belt, hairbrush or stick and (2) Threw or knocked him/her down. The scale had acceptable reliability (Cronbach's $\boldsymbol{\alpha}=.78$ ).

\section{Analytic Issues}

Because we were unable to obtain comparison shelter, prison, or domestic violence shelter samples for this study, a major concern was that the statistical tests be sufficiently sensitive. Sensitivity can become a problem when there is insufficient variability to explain in the data. For this reason, in replicating GrahamKevan and Archer (2003) we employed more sensitive tests. For example, rather than testing relationships between dichotomous variables in testing hypothesis 3 , we regressed the 2-cluster k-means solution on the percentage of the total violence that was male. Using continuous variables helps to retain variability in the sample.

Hypotheses were tested using the $R$ statistical programming package. Ordinary least squares regression was used to test Hypotheses 1, 2, 3, 5, 6, 7, 8,10 , and 11. Chi-square analyses were used to test Hypotheses 4 and 9 (also a logistic regression for hypothesis 9 ). Data quality problems were discovered with observation \#15, which was removed from the data.

\section{RESULTS}

Table 2 shows descriptive characteristics of the sample.

Table 2: Sample Characteristics

\begin{tabular}{|c|c|c|c|}
\hline Variable & $n$ & Mean & Standard Deviation \\
\hline Respondent female & 76 & $71 \%$ & .46 \\
\hline Respondent age & 76 & 22.13 & 2.11 \\
\hline Household Size & 76 & 3.59 & .79 \\
\hline Years of Education & 75 & 16.67 & 1.98 \\
\hline Total IPV & 76 & .18 & .69 \\
\hline Any IPV & 76 & $8 \%$ & .27 \\
\hline High Control Cluster & 76 & $9 \%$ & .29 \\
\hline IPV by mother & 76 & .05 & .36 \\
\hline IPV by father & 76 & .13 & .57 \\
\hline Percentage of IPV by male (among IPV cases) & 76 & .25 & .13 \\
\hline IPV injuries & 76 & $4 \%$ & .34 \\
\hline Patriarchal beliefs & 76 & 23.76 & 3.49 \\
\hline Acts of child abuse/ year & 76 & 2.11 & 3.52 \\
\hline Child Abuse Rate & 76 & $32 \%$ & .47 \\
\hline Achieved Control & 76 & 6.26 & 1.56 \\
\hline Harmony & 76 & 26.31 & 4.18 \\
\hline
\end{tabular}


Hypothesis 1 \& 3 . Consistent with hypotheses 1 and 3 , being in the high-control ( 7 cases) versus the lowcontrol cluster (69 cases) was significantly associated with more total violence $(\boldsymbol{\beta}=.58, p<.05)$ and more father to mother violence $(\boldsymbol{\beta}=.41, p<.01)$ in a bivariate regression. The cluster solution explained $6 \%$ of the variance in total violence and $11 \%$ of the variance in father to mother violence.

Table 3: OLS Regression. Total IPV

\begin{tabular}{|c|c|c|}
\hline Variable & $\boldsymbol{B}$ & SE $\boldsymbol{B}$ \\
\hline \hline Respondent age & -.01 & .037 \\
\hline Respondent female & .23 & .17 \\
\hline Household Size & .07 & .10 \\
\hline Years of Education & -.01 & .042 \\
\hline High Control Cluster & $.50 \dagger$ & .29 \\
\hline$R^{2}$ & & .09 \\
\hline
\end{tabular}

${ }^{\dagger} \mathrm{p}<.10{ }^{*} \mathrm{p}<.05 .{ }^{* *} \mathrm{p}<.01 .{ }^{* * *} \mathrm{p}<.001$.

Tables $\mathbf{3}$ and $\mathbf{4}$ show the results of OLS regression of total IPV frequency and father IPV frequency on the high-control cluster, controlling for respondent sex, age, household size, and the highest level of education in the household. Interestingly, when controls are introduced being in the high-control cluster is only marginally $(p<.10)$ positively associated with total IPV frequency but the positive association with father's IPV remains highly significant $(p=.01)$.

Table 4: OLS Regression. Father's IPV

\begin{tabular}{|c|c|c|}
\hline Variable & $\boldsymbol{B}$ & SE $\boldsymbol{B}$ \\
\hline \hline Respondent female & .05 & .09 \\
\hline Respondent age & .00 & .02 \\
\hline Household Size & .03 & .05 \\
\hline Years of Education & -.01 & .02 \\
\hline High Control Cluster & $.39^{*}$ & .15 \\
\hline Joint Significance $(F)$ & & \\
\hline$R^{2}$ & & .12 \\
\hline
\end{tabular}

${ }^{*} p<.05 .{ }^{* *} p<.01 .{ }^{* * *} p<.001$.

Hypothesis $3 a$ was not supported and results appear to be different from Straus (2008). There is no significant correlation between mother violence and control $(r=.09, n s)$ but a strong correlation between father violence and control $(r=.33, p<.01)$.

Hypothesis 2. A new variable was created which was the ratio of the father-to-mother violence to total violence scale, yielding a percentage measure of how much violence was father perpetrated. Consistent with hypothesis 2 , being in the high-control group was positively associated with the percentage of violence perpetrated by the father $(\boldsymbol{\beta}=.14, p<.01)$. Being in the high control group explained $10 \%$ of the variance in percentage of violence perpetrated by the father. Table 5 shows that this relationship holds $(\boldsymbol{\beta}=.12, p<.05)$ when respondent sex, age, and household size and highest level of education are controlled.

Table 5: OLS Regression. Percentage of IPV that is by Father

\begin{tabular}{|c|c|c|}
\hline Variable & $\boldsymbol{B}$ & SE $\boldsymbol{B}$ \\
\hline \hline Respondent female & .02 & .50 \\
\hline Respondent age & .00 & .91 \\
\hline Household Size & .01 & .56 \\
\hline Years of Education & .01 & .01 \\
\hline High Control Cluster & $.12^{*}$ & .05 \\
\hline$R^{2}$ & & .11 \\
\hline
\end{tabular}

${ }^{*} p<.05 .{ }^{* *} p<.01 .{ }^{* * *} p<.001$

Hypothesis 4. None of the participants reported that violence escalated, so the only possible comparison was between violence that stayed the same and violence that decreased over time. Chi-square analyses indicate that this is not related to control in these data $\left(\mathrm{x}^{2}=.02, d f=1, n s.\right)$.

Hypothesis 5. Regression indicated that being in the high-control cluster was marginally associated with more injuries $(\boldsymbol{\beta}=.24, p<.1)$. Being in the high control cluster explained $4 \%$ of the variance in injuries. However, this relationship was not significant when OLS regression with controls for respondent sex, age, household size, and highest education in household was run. This may indicate problems with statistical power.

Hypothesis 6. Regression indicated that being in the high-control group was not significantly or negatively associated with female violence in either the bivariate $(\boldsymbol{\beta}=.17, n s)$ or multiple regression case $(\boldsymbol{\beta}=.11, n s)$. In fact, the direction of the relationship is in the opposite direction to that proposed by the hypothesis.

Hypothesis $7 \& 8$. Regression indicated that college students from high-control families do not have significantly more patriarchal beliefs than other students $(\boldsymbol{\beta}=.53, n s)$. Neither did coming from a highcontrol family appear to have a relationship with 
participants ideals about family harmony $(\boldsymbol{\beta}=1.91, n s)$. However, as Table $\boldsymbol{6}$ indicates, this relationship became marginally significant when controls for household size, highest level of education, and respondent age and sex were introduced. $(\boldsymbol{\beta}=3.20, p$ $<.10)$. Hypotheses 7 was not supported. Hypothesis 8 had marginal support.

Table 6: OLS Regression. Family Harmony

\begin{tabular}{|c|c|c|}
\hline Variable & $\boldsymbol{B}$ & SE $\boldsymbol{B}$ \\
\hline \hline Respondent female & 1.58 & 1.06 \\
\hline Respondent age & -.02 & .23 \\
\hline Household Size & -.50 & .66 \\
\hline Years of Education & $-.55^{*}$ & .26 \\
\hline High Control Cluster & $-3.20 \dagger$ & 1.73 \\
\hline$R^{2}$ & & 0.11 \\
\hline
\end{tabular}

${ }^{\dagger} p<.10{ }^{*} p<.05 .{ }^{* *} p<.01 .{ }^{* * *} p<.001$.

Hypothesis 8a. However, in looking at the item-byitem Cronbach's alpha statistics for harmony, we discovered an apparent divergence. The first three items, concerning the importance of family harmony and self-censoring, appeared to be highly related and important. We speculated that the first three items might reflect a kind of hegemony or achieved control. This hypothesis was supported. When the first three items, measured as a scale, are regressed on the highcontrol group the regression coefficient is highly significant ( $\boldsymbol{\beta}=1.71, p<.01)$. Being in the high control cluster explained $10 \%$ of the variance in achieved control. As Table 7 shows, this relationship remained highly significant when controls were introduced.

Table 7: OLS Regression. Achieved Control

\begin{tabular}{|c|c|c|}
\hline Variable & $\boldsymbol{B}$ & SE $\boldsymbol{B}$ \\
\hline \hline Respondent female & .37 & .38 \\
\hline Respondent age & -.00 & .08 \\
\hline Household Size & $-.37 \dagger$ & .22 \\
\hline Years of Education & -.14 & .09 \\
\hline High Control Cluster & $-1.99^{* *}$ & .62 \\
\hline$R^{2}$ & & 0.17 \\
\hline
\end{tabular}

${ }^{\dagger} p<.10{ }^{*} p<.05 .{ }^{* *} p<.01 .{ }^{* * *} p<.001$

Hypothesis 9. Being from a high-control family was marginally related to child abuse $\left(\mathrm{x}^{2}=3.82, d f=1, p\right.$ $<.10)$. This is consistent with hypothesis 9. Logistic regression controlling for respondent age, sex, and household size and highest level of education showed similar results (Table 8). Respondents in the highcontrol cluster had 5.4 times higher odds of reporting child abuse $(p<.10)$.

Table 8: Logistic Regression. Child Abuse

\begin{tabular}{|c|c|c|}
\hline Variable & OR & SE B \\
\hline \hline Respondent female & .66 & .57 \\
\hline Respondent age & $.80 \dagger$ & .14 \\
\hline Household Size & 1.29 & .35 \\
\hline Years of Education & 0.96 & .14 \\
\hline High Control Cluster & $5.42 \dagger$ & .94 \\
\hline
\end{tabular}

${ }^{\dagger} p<.10{ }^{*} p<.05 .{ }^{* *} p<.01 .{ }^{* *} p<.001$.

Hypothesis 10. Participant ideals about family harmony were not at all related to total or father to mother violence, although coefficients were in the expected direction ( $\boldsymbol{\beta}=-.02, n s$. for total violence, $\boldsymbol{\beta}=$ .002 , ns. for father to mother violence). These results were also non-significant in multiple regression models.

Hypothesis 11. Unfortunately we were unable to measure the patriarchal beliefs of the parents so as to compare that relationship with reported marital violence. This makes impossible the use of multiple regression for this hypothesis. Thus, to evaluate hypothesis 11 we obtained Dr. Kim's nationally representative data set of Korean families (see Emery et al., 2012). For the Korean case, we expected the patriarchal beliefs measure to explain more of the variance in male violence than the controlling behaviors measure. This was not borne out by the data. In our data, being in the high-control group explained $11 \%$ of the variance in father to mother violence. However, patriarchal beliefs explained less than $1 \%$ of the variance in husband violence in Dr. Kim's sample ( $\boldsymbol{\beta}=$ .03, $p<.01)(\mathrm{n}=1537)$. A difference in proportions test $(\mathbf{Z}=-8.79, p<.001)$ is highly significant, but in the opposite direction to that predicted. Being in the high control group explains significantly more father to mother violence in our sample than patriarchal beliefs in the national sample. Several potential explanations of this will be considered in the discussion section.

\section{DISCUSSION}

\section{Controlling Behaviors Explain Substantially More Marital Violence than Patriarchal Beliefs}

Hypothesis 11 postulated that patriarchal beliefs would have more explanatory power than controlling 
behaviors in Korea. The logic was that patriarchal beliefs remain more salient in Korea and that the kinds of psychopathology that lead to Johnson-style (2008) intimate terrorism are comparatively rare. In fact, the opposite turned out to be the case. Although both were statistically significant predictors, patriarchal beliefs explained about half a percent of the variation in husband to wife violence, while controlling behaviors explained $11 \%$ of the variation in father to mother violence in our sample. The proportion of variance explained by controlling behaviors is more than 20 times larger than the proportion explained by patriarchal beliefs. A difference in proportions test indicates that this difference in percentages is highly significant.

There are several possible reasons for the results seen. It may be that Hypothesis 11 is simply wrong; that the role of the controlling behaviors scale in explaining marital violence is not substantially different from the west, and that the role of patriarchal beliefs does not differ substantially between Korea and Western countries. Indeed, one of the most important findings of this paper is that the controlling behaviors scale needs to be thoroughly studied in the Korean context. There are, however, other potential explanations, both substantive and methodological. The substantive explanations will be discussed here; the methodological alternative explanations will be discussed in the limitations section.

One alternative explanation for why the controlling behaviors scale has a much higher proportion of explained variance than the patriarchal beliefs scale is simply that one measures behaviors while the other measures beliefs. The gap between belief and behavior (sometimes called theory and practice) is well known. Behaviors may be better predictors of other behaviors than beliefs. This suggests a measure of behavioral indicators of patriarchal beliefs may be fruitful to develop.

Further, marital violence and the actual items on the controlling behaviors scale share two important and fundamental qualities. First, some of the items on the controlling behaviors scale are violent (e.g. smashing one's partner's property) just as marital violence is, by definition, violent. Second, some of the items on the controlling behaviors scale are abusive (e.g. humiliating the other partner), by which I mean the behaviors are intended to hurt the other partner in a way that is not considered legitimate or justified by the larger society. ${ }^{2}$ That one type of violent and abusive behavior would explain other types of abusive and violent behavior makes both intuitive and theoretical sense (see Ajzen, 2002; Emery et al., 2012). This, in fact, points to an inherent liability of the controlling behaviors scale. The relationship between marital violence and the items on the controlling behaviors scale may be somewhat tautological as a result of violent and abusive items in both the dependent and independent measures. Nonetheless, the role of controlling behaviors must be thoroughly investigated in future research on marital violence in Korea.

Many of our findings using Korean data are consistent with the findings of Graham-Kevan and Archer (2003). Consistent with hypotheses 1 and 3, participants who reported high amounts of controlling behaviors between their parents reported significantly higher levels of total marital violence and father to mother violence. Participants in the high controlling behaviors cluster reported significantly higher ratios of father-to-mother to total violence (hypothesis 2). Indeed, being in the high control cluster alone explained $10 \%$ of the variance in the ratio. This finding indicates controlling behaviors are not only associated with more violence, but that they are associated with proportionally more male violence. This would occur if men were more violent in the high control context, if women were less violent in the high-control context, or both that men were more violent and women were less violent. This finding is consistent with Johnson's (2008) claims about the nature of intimate terrorism. Also consistent with Graham-Kevan and Archer (2003) and Johnson's (2008) arguments, there was a marginally significant relationship between high control and injuries (hypothesis 5). These findings suggest both that the Graham-Kevan and Archer (2003) measure may be suitable for the Korean case. They also indirectly suggest that controlling violence is more severe than non-controlling violence for the Korean case, as well as the western case. This may mean that a vision of control motivated violence as rooted in psychopathology may not be inappropriate for the Korean case.

\footnotetext{
${ }^{2}$ This distinction is important. Leaving an abusive partner may well hurt, and be intended to hurt that partner. Leaving an abusive partner, however, is considered a legitimate response to abuse. Leaving an abusive partner cannot be defined as abusive when this safeguard is left in the definition. Simply defining abusive behavior as 'intentionally hurtful' behavior would be extremely problematic.
} 
Contrary to our hypothesis (7), being in the high control cluster was not significantly associated with offspring patriarchal beliefs. In a sense, this is bad news for our research, but it is good news for society. Growing up in a male dominated, controlling and possibly violent environment is not associated with offspring beliefs that legitimize that control. Offspring beliefs about family harmony were also not associated with being in the control cluster (hypothesis 8). However, when we re-conceptualize the first three Harmony items as achieved control (i.e. censor yourself in order to keep harmony), there is a strong and significant relationship between inter-parent controlling behaviors and achieved control of the offspring (hypothesis 8a). Being in the high control cluster explains $10 \%$ of the variance in achieved control. This suggests children may learn to silence themselves in high control contexts. Being in the high control cluster was also marginally associated with child abuse (hypothesis 9).

\section{Limitations}

There are a number of limitations that affect the strength of the conclusions that can be drawn from these analyses. First, the data are non-experimental, from a college student population and subject to reporter bias. The small sample size may have resulted in insufficient variation to substantiate some of the analyses which were not significant. For example, there was little variation in the responses to the question about escalation of violence. This may have impeded the finding of support for the escalation hypothesis (\#4). Support was not found for hypotheses $4,7,8$ or 10. For some hypotheses, this may have occurred due to a lack of variance in the data or statistical power, rather than true lack of relationship.

Hypothesis 11 was not supported because evidence was found in the opposite direction. Apart from the alternative substantive explanations proposed above, this finding is also subject to concerns about methodological artifacts. The patriarchal beliefs to marital violence versus controlling behaviors to marital violence could not be tested on the same data. Both the target population (nationally representative versus student sample) and the reporter (self/partner versus child witness) were different in the two samples. Indeed, as third parties it is possible that children may provide less biased accounts of marital violence than either parent. Thus, the finding could be an artifact of the method. However, the size of the difference between these two statistically significant ratios (20 times larger for controlling behaviors) mitigates against this concern. The size of the bias would have to be consistent and enormous to generate such a large effect size as an artifact.

Finally, these findings are preliminary and based on cross-sectional report data. The comparison of patriarchal beliefs to controlling behaviors has generated more questions than it has answered. Nonetheless, the answers to these questions are of vital importance if we are to understand the most important levers for intervention against marital violence in South Korea. The authors strongly encourage and intend systematic future research on the role of patriarchal beliefs, controlling behaviors and martial violence in Korea.

\section{CONCLUSION}

Our preliminary findings suggest that controlling behaviors are highly correlated with marital violence in Korea, and that the characteristics of the violence differ substantially in high-control versus low-control contexts. The evidence is largely consistent with Johnson's (2008) claims about the distinction between situational (common) couple violence and intimate terrorism. Future research is needed to concretely evaluate and establish the role of controlling behaviors in marital violence for the Korean context. Indeed, going forward we would suggest that all research attempt to make this distinction between different types of marital violence.

In particular, research into the etiology of the motivation to control is desperately needed, both for the purposes of prevention and because different etiologies may have very different implications for victims. To what extent is control motivated by deepseated emotional needs for security versus a simple need to save face in a patriarchal context? The answer to this question has implications both for the necessary requirements to reduce intimate terrorism and for the frequency, severity and context of the violence.

If we are to truly face and demolish the scourge of marital violence in society, our understanding of that violence must be nuanced, subtle, and thorough. Our understanding of the etiology underlying Johnson's (2008) control based typology remains very superficial, and it may well be the case that the typology itself is insufficiently nuanced. ${ }^{3}$ A very basic first step will be to thoroughly examine the typological distinctions, and the

\footnotetext{
${ }^{3}$ See Emery, 2011.
} 
role of controlling behaviors and patriarchally motivated behaviors in theoretically sophisticated, culturally informed, and empirically rigorous research.

\section{ACKNOWLEDGEMENT}

We wish to thank the Yonsei University Research
Office, NSFC grant 71002014, NSFC-NRF 71111140395, and Professor Yong Suhk Pak for Support.

\section{REFERENCES}

Ajzen, I. (2002). Perceived Behavioral Control, Self-Efficacy, Locus of Control, and the Theory of Planned Behavior. Journal of Applied Social Psychology, 32(4): 665-683. http://dx.doi.org/10.1111/j.1559-1816.2002.tb00236.x

Browning, C. (2002). The span of collective efficacy: Extending social disorganization theory to partner violence. Journal of Marriage and Family, 64(11): 833-850. http://dx.doi.org/10.1111//j.1741-3737.2002.00833.x

Cassidy, J. \& Shaver, P. (1999). Handbook of attachment: Theory, research and clinical applications. New York, NY: The Guilford Press.

Chang, K. (2003). The state and families in South Korea's compressed fertility transition: A time for policy reversal? Journal of Population Security, 1(s):596-609.

Emery, C. (2007). Consequences of Childhood Exposure to Intimate Partner Violence. University of Chicago. Unpublished doctoral dissertation.

Emery, C., Kim, J., Song, H., Song, A. (2012). Child Abuse as a Catalyst for Wife Abuse? Journal of Family Violence, in press.

http://dx.doi.org/10.1007/s10896-012-9480-y

Emery, C. (2011). Disorder or Deviant Order? Aggression and Violent Behavior, 16(6): 525-540. http://dx.doi.org/10.1016/j.avb.2011.07.001

Gover, A., Jennings, W., Tomsich, E., Park, M. \& Rennison, C. (2011). The influence of childhood maltreatment and selfcontrol on dating violence: A comparison of college students in the United States and South Korea. Violence and Victims, 26(3): 296-318.

http://dx.doi.org/10.1891/0886-6708.26.3.296

Graham-Kevan, N. \& Archer, J. (2003). Intimate terrorism and common couple violence: A test of Johnson's predictions in four British samples. Journal of Interpersonal Violence, 18(11): 1247-1270. http://dx.doi.org/10.1177/0886260503256656

Hamby, S., Finkelhor, D., Turner, H. \& Omrod, R. (2010). The overlap of witnessing partner violence with child maltreatment and other victimizations in a nationally representative survey of youth. Child Abuse \& Neglect 34(3): 734-741.

http://dx.doi.org/10.1016/j.chiabu.2010.03.001

Heller, P. (1976). Familism Scale: Revalidation and Revision. Journal of Marriage and Family, 38(3): 423-429. http://dx.doi.org/10.2307/350410

Hogarth, H. (nd). Matrifocality in Korean society: Hindrance or help towards gender equality? The Royal Anthropological
Institute. $\quad$ 6-12-2012 from: http://sydney.edu.au/arts/korean/downloads/KSAA2009/Glob al_Korea_Proceedings_104-114_Hogarth.pdf

Holtzworth-Munroe, A. \& Stuart, G. (1994). Typologies of male batterers: Three subtypes and the differences among them. Psychological Bulletin, 116(3): 476-497. http://dx.doi.org/10.1037/0033-2909.116.3.476

Holtzworth-Munroe, A., Meehan, J., Herron, K., Rehman, U. \& Stuart G. (2000). Testing the Holtzworth-Munroe and Stuart (1994) batterer typology. Journal of Consulting and Clinical Psychology, 68(6): 1000-1019. http://dx.doi.org/10.1037/0022-006X.68.6.1000

Johnson, M. (2008). A Typology of Domestic Violence. Lebanon, NH: Northeastern University Press.

조춘범. (2007). 청소년의 부부폭력 노출경험이 인터넷 중독에 미치는 영향.

Kim, J. \& Sung, K. (2000). Conjugal Violence in Korean American Families: A Residue of the Cultural Tradition. Journal of Family Violence, 15(4): 331-345. http://dx.doi.org/10.1023/A:1007502212754

김재엽, 김희진, \& 최장원. (2010). 직장 남성의 가부장적 성역할 태도와 아내 폭력의 관계에서 나타난 긍정적 의사소통(TSL)의 조절효과. [A Study on Moderating Effect of Marital Communication(TSL) on Male Workers' Gender Role Attitudes and Wife Abuse]. 스피치와 커뮤니케이션(13), 3970.

김재엽, 최재성, Emery, C., 김동구, 박상언, 정윤경, 이정은(2010). 2010년 가정 폭력 실태조사. 여성가족부. A report to the Korean Ministry of Women and Families.

김정옥, 전형미, 이현혜. (1992). 자아존중감, 부부간 의사소통 및 결합력이 아내학대에 미치는 영향. 여성문제연구. 20(1),2144.

Lim, T. \& Choi, S. (1996). Interpersonal relationships in Korea. In W Gudykunst, S. Ting-Toomey, \& T. Nishida (Eds.) Communication in personal relationships across cultures. London: Sage.

Ornatowski, G. (1996). Confucian Ethics and Economic Development: A Study of the Adaptation of Confucian Values to Modern Japanese Economic Ideology and Institutions. Journal of Socio-Economics, 25(5): 571-590. http://dx.doi.org/10.1016/S1053-5357(96)90018-9

Pence, E. \& Paymer, M. (1993). Education Groups for Men Who Batter. The Duluth Model. New York, NY: Springer.

Straus, M. (2008). Dominance and symmetry in partner violence by male and female university students in 32 nations. Children and Youth Services Review, 30, 252-275. http://dx.doi.org/10.1016/j.childyouth.2007.10.004

Straus, M., Hamby, S., Boney-McCoy, S. \& Sugarman, D. (1996) The Revised Conflict Tactics Scales (CTS2). Development and Psychometric Data. Journal of Family Issues, 17(3): 283316.

http://dx.doi.org/10.1177/019251396017003001

Straus, M. \& Mattingly, M. (2007). A Short Form and Severity Level Types for the Parent-Child Conflict Tactics Scales. Family Research Laboratory Publication NH 03824

Received on 02-07-2012

Accepted on 27-12-2012

Published on 31-12-2012

DOI: http://dx.doi.org/10.6000/1929-4409.2012.01.22

(C) 2012 Emery et al.; Licensee Lifescience Global.

This is an open access article licensed under the terms of the Creative Commons Attribution Non-Commercial License (http://creativecommons.org/licenses/by-nc/3.0/) which permits unrestricted, non-commercial use, distribution and reproduction in any medium, provided the work is properly cited. 